\title{
Materialism, Depression, and Compulsive Buying among
}

\section{University Students}

\author{
Nimra Iqbal $^{1 *}$, Naeem Aslam ${ }^{1}$
}

\section{ABSTRACT}

This paper examined the relationship of materialism, depression and compulsive buying among university students. Moreover, it aimed to see the role of demographic variables in the relationship between these variables. Material Value Scale (Richins \& Dawson, 1992), Compulsive Buying Scale (O'Guinn \& Faber, 1989) and the subscale of depression of DASS (Lovibond \& Lovibond, 1995) were used to measure materialism, compulsive buying and depression respectively. The sample comprised of 430 university students within the age range of 18 to 24 years $(M=21.55, S . D=1.95)$ from five universities of Islamabad and Rawalpindi. A significant positive relationship between depression and materialism was found. A significant difference between males and females on materialism and depression was found with males scoring significantly higher on both as compared to females. However, no significant difference was found between males and females compulsive buying. There was a significant difference among adolescents and adults on materialism with adults scoring higher as compared to adolescents, while no significant differences were found on depression and compulsive buying.

Keywords: Materialism, Depression, Compulsive Buying.

A growing amount of people are engaged in excessive amount of buying material goods that create considerable effect on a person's life and it may lead to distress and uncontrollable behavior (Benson, 2000; Dittmar, 2004b). This behavior is referred to as compulsive buying behavior which is becoming a center of attention for the researchers (Black, 2004; Faber, 2004; Dittmar, 2004b). Presently, a large amount of people are involved in compulsive buying especially in USA, UK and Germany (Yurchisin \& Johnson, 2004). The occurrences of compulsive buying have increased noticeably in recent years around the world and have become a burning issue among researchers (Koran, Faber, Aboujaoude, Large, \& Serpe, 2006; Ridgway, Kinney, \& Monroe, 2008; Neuner, Raab, \& Reisch, 2005).

\footnotetext{
${ }^{1}$ National Institute of Psychology, Quaid-i-Azam University, Islamabad, Pakistan

*Responding Author

(C) 2016 I N Iqbal, N Aslam; licensee IJIP. This is an Open Access Research distributed under the terms of the Creative Commons Attribution License (http://creativecommons.org/licenses/by/2.0), which permits unrestricted use, distribution, and reproduction in any Medium, provided the original work is properly cited.
} 
A compulsive buyer is a person who has a strong and unmanageable desire to obtain possessions (Edwards, 1993; Faber \& O’ Guinn, 1992; Goldsmith \& McElroy, 2000). Compulsive buying behavior generally occurs from a depressive mental state and it is usually followed by an enduring and frequent buying behavior (Miltenberger et al., 2003; Faber \& O’Guinn, 1989). Past researchers have found that a greater amount of money accountability has been caused by the individuals who buy compulsively (Christenson et al., 1994; Edwards, 1993; Faber \& O’Guinn, 1988). Consequently, compulsive buying is becoming a global problem (Neuner, Raab \& Reisch, 2005; Ridgway, Kinney, \& Monroe, 2008). Furthermore, it was found that individuals who are highly money oriented have a strong urge to consume more possessions than others (Dittmar, Beattie, \& Friese, 1996).

Materialism is defined as an individual's practice to obtain money, status and belongings (Kasser, Ryan, Couchman, \& Sheldon, 2004). It is a combination of principles which regards materialistic goals as a symbol of achievement; whereas the goods are considered to be an important part of life and more goods will provide more satisfaction. Materialistic individuals consider attainment of possessions as the foremost goal of life (Richins \& Dawson, 1992).

Materialistic values and compulsive buying are interrelated (DeSarbo \& Edwards, 1996; Dittmar, 2005; Mowen \& Spears, 1999; Mick, 19960’Guinn\& Faber, 1989; Yurchisin \& Johnson, 2004). Dittmar, Beattie, and Friese (1996) have studied the association between compulsive buying tendencies and use of specific buying considerations, the consumption of possessions as an accomplishment and the quantity of self-discrepancy between real and ideal self. Results reveal that people who are prone to become compulsive buyers have high materialistic value orientation (Richins \& Dwason, 1992). Yurchisin and Johnson (2004) have argued that the likelihood of worth linked to material possession is the forecaster of compulsive consumption.

Compulsive buyers are anticipated to be materialistic in nature (Dittmar, Beattie, \& Friese, 1996; Mowen\& Spears, 1999; O’Guinn \& Faber, 1989) and females have a greater likelihood to become compulsive buyers than males (O’Guinn \& Faber, 1989; Roberts, 1998; Schlosser, Repertinger, \& Freet, 1994). Various studies have established a contradictory link between materialism and compulsive buying. Materialistic value is a belief that the achievement of material goods is a fundamental goal of life, a sign of accomplishment and a way to satisfaction (Richins, 2004). Past researches have ignored the role of materialism on compulsive buying as if they are not associated to each other (Scherhorn, Reisch \& Raab, 1990) while materialism and depression are interrelated (O'Guinn \& Faber, 1989). Very recent studies have found a significant relationship between materialism and compulsive buying. Dittmar (2005) demonstrated that an individual's materialistic value strongly predicts his compulsive buying behavior.

Depression is described as a state of low self-esteem and lack of motivation towards one's self in order to determine the likelihood to accomplish life goals which are essential to a person 
(Lovibond \& Loviboond, 1995). Depressive people usually show inferiority feelings, unhappiness and they perceive themselves to be weak (Beck et al., 1961). Compulsive buying tendencies are positively associated with materialism and depression (Mueller et al., 2011). Some cross-sectional studies have also tried to establish link between compulsive buying and other psychological factors like materialism (Dittmar, 2005; Mueller et al., 2011; Rose, 2007), anxiety, and depression (Lejoyeux, Tassain, Solomon, \& Adès, 1997; Mueller et al., 2010). Past researchers suggest that compulsive buying is a result of an individual's effort to deal with a negative mood (DeSarbo \& Edwards, 1996; Miltenberger et al., 2003). Compulsive buying has also been linked with mental comorbodities, predominantly with depression and anxiety (Mueller et al., 2010). It has also been linked with anxiety, distress, and a low mental well-being (Williams, 2012). It was found that compulsive buying act as a mood enhancer for the individuals who face negative emotions (Faber \& Christenson, 1996). Materialism has been linked to negative signs of relieve like loneliness (Pieters, 2013), distress (Mueller et al., 2011), and low self-worth (Christopher et al., 2006; Richins\& Dawson, 1992).

A lot of empirical literature suggests that as a result of globalization, consumer culture is increasing rapidly and bringing negative consequences in the form of compulsive buying tendencies and materialism, and it is becoming a global problem (Bushra \& Bilal, 2014). There exists scarcity of research in Pakistan which concerns the mechanisms underlying the relationships among materialism, compulsive buying and depression. So as to fill the gap that exists within this field in Pakistan, these variables need to be explored further (Jalees, Amen, \& Kazmi, 2014).

Studies have found that the onset of compulsive buying, or the tendencies appear in the late teens or early twenties (Christensen et al., 1994; Koran et al., 2002; Schlosser et al., 1994). One of the major aim of the present study is to investigate the age in which compulsive buying behavior is prevalent in our society. Additionally, compulsive buyers are inclined to have higher levels of depression (Black, 2007; Christenson et al., 1992; Dittmar, 2005; McElroy et al., 1994; Scherhorn et al., 1990; Valence, d'Astous, \& Fortier, 1988), and higher levels of obsessions and anxiety (Black, 2007; Dittmar, 2005; McElroy et al., 1994; O’Guinn \& Faber, 1989; Scherhorn et al., 1990). Therefore the role of depression was also explored. Further research has established that female fall into the category of compulsive buying more than males (Black, 2007; Christenson et al., 1992; D’Astous, 1990; O’Guinn \& Faber, 1992; Scherhorn et al., 1990). Hence, another purpose of the study is to explore whether gender differences exist for the variables, as per the literature.

An important point to consider is that this study is being conducted in Pakistan, while existing literature and studies, based on similar topics were carried out in Western Countries. As per Chan and Predergast (2007), there may be a difference in the results due to cultural differences. Owing to this factor, future studies should be conducted including Western and Asian participants. 


\section{OBJECTIVES}

The study has the following objectives.

1. To explore the relationship between materialism, depression and compulsive buying among university students.

2. To explore the role of demographic variables in the relationship between materialism, compulsive buying and depression among university students.

\section{Hypotheses}

1. There would be a positive relationship between materialism, compulsive buying and depression among university students.

2. Age is negatively linked with compulsive buying and depression while positively associated with materialism.

3. Women would score higher on materialism, depression and compulsive buying as compared to men.

4. Adults would score higher on materialism and lower on depression as compared to adolescents.

\section{METHOD}

\section{Participants}

The sample included 430 university students from five universities of Islamabad i.e. COMSATS Institute of Information Technology, Quaid-i-Azam University, Iqra University, Bahria University and National University of Modern Languages. Participants were enrolled in the Graduate, Masters or M.Phil programs. The age of the sample was ranged from 18 to 24 years $(M=21.55, S . D=1.95)$. The students fulfilling these criteria were made a part of the present study with their consent.

\section{Measures}

Material Values Scale (MVS). Richins and Dawson's (1992) Material Values Scale (MVS) was used to evaluate participants' level of materialism. This scale takes materialism as a value that influences a person's interpretation of life and environment (Richins, 2004). It has three facets: centrality, success, and happiness. The 15-item version was used in the present study. Alpha reliability of the scale is .86 (Richins, 2004).Scoring is based on 5-point likert scale (i.e. $1=$ strongly disagree and 5=strongly agree). Reverse scored items are 3, 6, 7, 10, 14, and 15. Two more items were also identified as reverse scored after the experts' opinion and identification. Prior applications of the MVS suggested that its psychometric properties suffered when it was applied in East Asian settings because of the use of some reverse-worded items (Wong, Nancy, Rindfleisch \& Burroughs, 2003). Co-efficient alpha for the present sample was .71 demonstrating good internal reliability.

Depression Anxiety Stress Scale (DASS). It is a 42-item questionnaire which was developed by Lovibond (1995). It included three subscales designed to measure depression, anxiety and stress. Its reliability coefficient is .92 (Lovibond \& Lovibond, 1995).Each subscale contains 14 items. In the present study, the subscale of depression was used only. The Depression scale 
evaluated dysphasia, devaluation of life, hopelessness, self-deprecation, lack of interest/involvement, anhedonia, and inertia. 4-point likert scale from 0 (not at all) to 3 (all the time) was used to rate the amount to which a person experience each state over the past week. Possible score range for depression subscale is between 0 to 42. Co-efficient alpha was .86 for the present sample which demonstrates high internal consistency.

The Compulsive Buying Scale (CBS).It was developed by Faber and O’Guinn (1992). CBS was designed to screen for the problem of compulsive buying within the general population and was developed using a phenomenological approach. In the present study, likert-type scale with 5 points (strongly disagree-strongly agree and never-very often) was adopted. Higher scores on the CBS indicated a higher level of compulsive buying (Kwak, Zinkhan, \& Dominick, 2002; Mueller et al., 2011). Minor adaptations were made in the comprehension of some items for the ease and cultural appropriateness. For the present sample, the co-efficient alpha was .77.

\section{Procedure}

The study was conducted in the universities within Islamabad. After taking permission from the authorities of each institute, the participants i.e. students were individually approached through the technique of convenient sampling. Informed consent was obtained from each participant and they were briefly explained about the purpose of the research. Each participant was provided with a copy of the demographic sheet, MVS, Depression subscale (DASS) and CBS. Instructions in both verbal and written form were given to the participants to fill the questionnaires. The participants were also told that they had the right to withdraw from participation at any point, if they felt unwilling or uncomfortable, although full participation was highly encouraged.

\section{RESULTS}

\section{Descriptive Statistics and Psychometric Properties}

The instruments used for this paper had established reliabilities and validities, but the same were re-assured in Pakistani perspective. The summarized reliabilities and descriptive statistics based on Cronbach alpha are presented in Table 1.

Table 1, Descriptive Statistics and Skewness for Material Value Scale, Depression (subscale) of DASS and Compulsive Buying Scale $(N=430)$

\begin{tabular}{|l|c|c|c|c|c|c|}
\hline & & & \multicolumn{2}{|c|}{ Ranges } & \\
\hline \multicolumn{1}{|c|}{ Scales } & $\begin{array}{c}\text { No of } \\
\text { items }\end{array}$ & $\alpha$ & $\boldsymbol{M}(\mathbf{S D})$ & Potential & Actual & Skewness \\
\hline MVS & 15 & .71 & $48.71(9.8)$ & $15-75$ & $27-75$ & 0.68 \\
\hline D(DASS) & 14 & .86 & $12.51(8.3)$ & $0-42$ & $0-40$ & 0.43 \\
\hline CBS & 7 & .77 & $18.94(6.4)$ & $7-35$ & $7-32$ & 0.43 \\
\hline
\end{tabular}

Note. MVS = Material Value Scale; D = Depression subscale; DASS = Depression Anxiety Stress Scale; CBS = Compulsive Buying Scale; $\alpha=$ Alpha reliability 
In order to determine the descriptive statistics on scales of materialism, Depression (subscale) and compulsive buying, descriptive statistics were computed. Table 1 illustrates the results of mean, standard deviation and skewness for Material Value Scale (MVS), Depression (subscale) of Depression Anxiety and Stress Scale (DASS) and Compulsive Buying Scale (CBS). It was observed that the scales used in the present study had their skewness within the desired range of 1 to +1 . As indicated by table 3, the value of Alpha was depicting high internal consistency of the instruments i.e. ranging from .71 to .86. The values of S.D indicated that the responses were scattered from the mean of each variable. Positive values for skewness indicated asymmetrical distribution of data along the mean value.

Findings of Hypothesized Relationships

Table 2, Pearson Correlation between Materialism, Depression and Compulsive Buying $(N=$ 430)

\begin{tabular}{|l|l|l|l|}
\hline Variables & $\mathbf{1}$ & $\mathbf{2}$ & $\mathbf{3}$ \\
\hline 1. Materialism & - & & \\
\hline 2 .Depression & $.15^{* *}$ & - & \\
\hline 3 .Compulsive Buying & -.01 & .07 & - \\
\hline
\end{tabular}

$* * p<.01, * p<.05$

Table 2 shows that Pearson correlation between materialism, depression and compulsive buying. It is showed that there was a significant positive relationship between depression and materialism ( $r=.15, p<.01$ ) which indicated that more the participants were materialistic, more was the level of depression. Whereas the relation between depression and online compulsive buying was nonsignificantly positive $(r=.07)$. Results also showed a non-significant negative relationship between materialism and compulsive buying ( $r=-.01)$.

Table 3, Mean, Standard Deviation and $t$ values for Males and Females on Materialism, Depression and Compulsive Buying $(N=430)$

\begin{tabular}{|c|c|c|c|c|c|c|c|}
\hline \multirow[b]{3}{*}{ Measures } & \multirow{3}{*}{$\begin{array}{c}\text { Men } \\
(n=183) \\
M(S D)\end{array}$} & \multirow{3}{*}{$\begin{array}{c}\text { Women } \\
(n=247) \\
M(S D)\end{array}$} & \multirow[b]{3}{*}{$t(430)$} & \multirow[b]{3}{*}{$p$} & \multirow{2}{*}{\multicolumn{2}{|c|}{$95 \% C I$}} & \multirow{3}{*}{$\begin{array}{c}\text { Cohen's } \\
\text { d }\end{array}$} \\
\hline & & & & & & & \\
\hline & & & & & $L L$ & $U L$ & \\
\hline MVS & $51.26(8.51)$ & $46.83(10.40)$ & 4.70 & .001 & 2.57 & 6.27 & .46 \\
\hline Depression & $14.45(7.77)$ & $11.06(8.53)$ & 4.22 & .001 & 1.81 & 4.96 & .41 \\
\hline CBS & $19.22(6.00)$ & 18.74(6.69) & .78 & .43 & -.74 & 1.71 & .07 \\
\hline
\end{tabular}

Note. MVS = Material Value Scale; CBS = Compulsive Buying Scale. $M=$ Mean; $S D=$ Standard deviation; $L L=$ Lower limit; $U L=$ Upper limit; $C I=$ Confidence interval. 
Table 3 shows mean differences between men and women on materialism, depression and compulsive buying. Results indicated significant difference between men and women on materialism $(t(430)=4.70, p<.001)$. Men's mean $(M=51.26)$ was higher than the women's mean $(M=46.83)$. Results also showed significant mean difference on depression $t(430)=4.22$, $p<.001$. Men's mean $(M=14.45)$ was higher than the women's mean $(M=11.46)$. There was no significant difference between mean of men and women on scores of compulsive buying $t$ (430) $=.78$.

Table 4, Mean, Standard Deviation and T Values for Adolescents and Adults on Materialism, Depression and Compulsive Buying $(N=430)$

\begin{tabular}{|c|c|c|c|c|c|c|c|}
\hline \multirow[b]{3}{*}{ Variables } & \multirow{3}{*}{$\begin{array}{c}\text { Adolescents } \\
(n=125) \\
M(S D)\end{array}$} & \multirow{3}{*}{$\begin{array}{c}\text { Adults } \\
(n=305) \\
M(S D)\end{array}$} & \multirow[b]{3}{*}{$t(430)$} & \multirow[b]{3}{*}{$p$} & \multirow{2}{*}{\multicolumn{2}{|c|}{$95 \% C I$}} & \multirow[b]{3}{*}{ Cohen's d } \\
\hline & & & & & & & \\
\hline & & & & & $L L$ & $U L$ & \\
\hline Materialism & 46.69(9.38) & 49.54(9.97) & 2.73 & .01 & -4.89 & -.80 & -.29 \\
\hline Depression & 13.41(8.33) & $12.15(8.38)$ & 1.40 & .16 & -.49 & 3.00 & .15 \\
\hline $\begin{array}{l}\text { Compulsive } \\
\text { Buying }\end{array}$ & 19.08(6.87) & $18.89(6.22)$ & .27 & .78 & -1.15 & 1.52 & .02 \\
\hline
\end{tabular}

Note. $M=$ Mean; $S D=$ Standard deviation; $L L=$ Lower limit; $U L=$ Upper limit; $C I=$ Confidence interval.

Table 4 shows mean differences between adolescents and adults on materialism, depression and compulsive buying. Two groups of the age were made. One group was ranging from 18-20 years (adolescents) and other was ranging from 21-24 years (adults). There was a significant difference on materialism $t(430)=2.73, p<0.01$. Mean of adults $(M=49.94)$ was higher than the mean of adolescents $(M=46.69)$. In addition, no significant differences was found between adolescents and adults on depression and compulsive buying.

\section{DISCUSSION}

Results demonstrated that materialism had a positive relationship between materialism and depression. This result supported most of the previous findings that had explored the relationship between depression and materialism and found a considerable association between higher levels of materialism and higher levels of depressive symptoms (Burroughs \& Rindfleisch, 2002; Kasser\& Ryan, 1993, 1996; Schor, 2004). Results found no significant relationship between compulsive buying and materialism. The result supported some other previous findings in which no relationship existed between materialism and compulsive buying behavior (Jalees et al., 2014). Results also indicated no significant relationship between depression and compulsive buying. It has been evident from the previous study that there was no condition in either positive 
or negative affect following the buying task. Therefore compulsive buying may not always be a result of depression (Williams, 2012).

Results revealed that there was a non-significant negative association between age and compulsive buying which was contrary to the previous researches thatshowed a negative association between age and compulsive buying (Koran et al., 2006; Mueller et al., 2010; Neuner, Raab, \& Reisch, 2005). Researches also showed that compulsive buying usually manifested itself in the late teens and early 20's (Black, 2007; Dell'Osso, Altamura, Allen, Marazziti, \& Hollander, 2006), and the rates tended to go lower after that (Dittmar, 2005). Results also found a non-significant negative relationship between age and depression which was contrary to the previous literature that had found an increased prevalence of depression among adolescents (El-Missiry, 2012; Fan, 2011; Sarkar, 2012). The result supports the hypothesis that age and materialism have a positive relationship. This finding was in line with earlier studies that found an increase in materialistic values with age (Moore \& Moschis, 1981).

The results revealed a significant difference among men and women on materialism and depression and found that men scored significantly higher than women on materialism. The previous studies supported this result and confirmed that men had stronger orientation towards materialistic values as compared to women (Achenreiner, 1997; Churchill \& Moschis, 1979; Moore \& Moschis, 1981). The results of the present research also found that men scored significantly higher than women on depression. Previous studies showed that in nontraditional sex-role, men were found to have higher levels of depressive symptoms than women (Rosenfield, 1980) which supported the results of the present study. No significant difference was found between men and women on compulsive buying. Billieux et al. (2008) found that no significant gender differences were found for compulsive buying behavior which was in line with our results.

Fourth main objective of the present research was to explore the differences among adolescents and adults on materialism and depression. Results revealed that the mean of adults on materialism was significantly higher than the mean of adolescents (Table 4). This confirmed the first part of fourth hypothesis. Earlier studies had found that materialistic group was generally older than the non-materialistic group (Yiqiu, 2005). Another study found that age group between 15 to 19 years old was less materialistic while age group of 20 to 29 years old was more materialistic (Kau et al., 2000). The results of the present study also showed that adolescents scored higher on depression but the results were no significant while previous studies found an increased prevalence of depression among adolescents (El-Missiry, 2012; Fan, 2011; Sarkar, 2012).

In conclusion, the present research has shown no significant relationship between compulsive buying and materialism. Moreover, the study found a relationship between materialism and 
depression. Some of the results remained consistent with the previous researches. Based on these results, we can conclude that compulsive buying is a growing concern of consumer culture in Pakistan. The findings of the present study can help in providing theoretical basis for further researches in Pakistan.

\section{LIMITATION AND SUGGESTIONS}

Research is an ongoing process. The limitations of this research may provide future directions for other researches. First limitation of this study was the short span of time. Research can be replicated in longer span of time for a broader view. The present study was conducted with the help of already developed psychometric scales which are extensively used by many researchers. Self-report measures have been used in the present study. So, there is a chance of inaccurate selfreporting, social desirability bias and errors in self-observation. Our results were also confined by the correlational nature of our data. Because of this, we cannot absolutely establish a causal link between materialism and compulsive buying. This is an important restraint facing nearly all researches in this area. As suggested by Richins and Dawson (1992), the link between materialism and compulsive buying may be bidirectional. Thus, studies that are able to unfold the underlying relationship between these two variables have the potential to make an important role. Sample was limited to only two cities i.e. Rawalpindi and Islamabad. So, there is uncertainty in generalizing the finding of the present study. Additionally, students were studied only at three level of undergraduate, masters and M. Phil. Future studies could cover other cities of Pakistan as well, particularly considering that it has a rich and ethnically diversified culture. To confirm the results future studies require more comprehensive investigation of relationship between the variables.

\section{IMPLICATIONS OF THE STUDY}

To investigate the causal linkage between materialism, depression and compulsive buying, further effort is required. As compulsive buying became the centre of attention for marketers and scholars all over the world, efforts have been made to study the relationship of compulsive buying with materialism and depression. However, there is scarcity of research in Pakistan concerning this area. With the best of researcher's knowledge, there was no available data in Pakistan on the relationship between materialism, depression and compulsive buying, proposing new perspective in this area. The findings of present study provide a few implications for researchers and policy makers. For young consumers, parental and social guidance is needed.

As discussed earlier, that due to globalization, consumer culture is spreading rapidly around the globe, as consumers in the developing countries are progressively becoming influenced by it and that it has considerable negative aspects to it on a community level in the form of compulsive buying and materialism leading to affect the consumers in anundesirable way in the form of depression. 
This is an alarming state for the consumer safety organizations to make the public alert of the adverse outcomes of the materialistic values in the society and direct them through public service messages or marketing campaigns to make rational decision-making with respect to their purchases.

\section{REFERENCES}

Benson, A. (Ed.). (2000). I shop therefore I am: Compulsive buying and the search for self. New York: Aronson.

Black, D. W. (2004). Compulsive shopping. In E. Hollander (Ed.), Handbook of impulse control disorders. American Psychiatric Publishing.

Black, D. W. (2007). A review of compulsive buying disorder. World Psychiatry, 6(1), 148.

Bushra, A. \& Bilal, A. (2014). The Relationship of Compulsive Buying with Consumer Culture and Post-Purchase Regret, Pakistan Journal of Commerce and Social Sciences, 8(3), 590611.

Chan, K. \& Prendergast, G. (2007). Materialism and social comparison among adolescents. Social Behavior and Personality, 35(2), 213-228.

Christenson, G. A., Faber, R. J., Zwaan, M., Raymond, N. C., Specker, S. M., Ekern, M. D., Mackenzie, T. B., Crosby, R. D., Crow, S. J., Eckert, E. D., Mussell, M. P., \& Mitchell, J. E. (1994). Compulsive buying: Descriptive characteristics and psychiatric comorbidity. Journal of Clinical Psychiatry, 55(1), 5-11.

Christopher, A. N., Drummond, K., Jones, J. R., Marek, P., \&Therriault, K. M. (2006). Beliefs about one's own death, personal insecurity, and materialism. Personality and Individual Differences, 40, 441-451.

D'Astous, A. (1990). An inquiry into the compulsive side of normal consumers. Journal of Consumer Policy, 13, 15-31.

DeSarbo, W., \& Edwards, E. (1996). Typologies of compulsive buying behaviour: A constrained clusterwise regression approach. Journal of Consumer Psychology, 5(3), 231-262.

Dittmar H. (2005). Compulsive buying - A growing concern? An examination of gender, age, and endorsement of materialistic values as predictors. British Journal of Psychology, 96(4), 467-91.

Dittmar, H. (2004b). Understanding and diagnosing compulsive buying. In R. Coombs (Ed.), Handbook of addictive disorders: A practical guide to diagnosis and treatment. New York: Wiley.

Dittmar, H. (2005). A new look at "compulsive buying": Self-discrepancies and materialistic values as predictors of compulsive buying tendency. Journal of Social and Clinical Psychology, 24(6),832-59.

Dittmar, H., Beattie, J., \&Friese, S. (1996). Objects decision considerations and self image in men's and Women's impulse purchases. ActaPsychologica, 93, 187-206.

Edwards, E. A. (1993). Development of a new scale for measuring compulsive buying behavior. Financial Counseling and Planning, 4, 67-84. 
Faber, R. J., \& O’ Guinn, T. C. (1992). A clinical screener for compulsive buying. Journal of Consumer Research, 19, 459-469.

Faber, R., \& Christenson, G. (1996). In the mood to buy: Differences in the mood states experienced by compulsive buyers and other consumers. Psychology and Marketing, 13(18), 803-820.

Faber, R., \&O'Guinn, T. (1988). Compulsive Consumption and Credit Abuse, Journal of Consumer Policy, 11(1), 97-109.

Goldsmith, T., \& McElroy, S. L. (2000). Diagnosis, associated disorders, and drug treatment. In A. L. Benson (Ed.), I shop, therefore I am: Compulsive buying and the search for self (217-241). Northvale, NJ: Jason Aronson Inc.

Jalees, T., Amen, U. \&Kazmi, Q. (2014). A structural approach on compulsive buying. Institute of Business Administration Karachi, 1-24.

Kasser, T., Ryan, R. R., Couchman, C. E., \& Sheldon, K. M. (2004). Materialistic values: Their causes and consequences. In T. Kasser\& A. Kanner (Eds.), Psychology and Consumer Culture: The struggle for a good life in a materialistic world (pp. 11-28). Washington, DC: American Psychological Association.

Koran, L. M., Faber, R. J., Aboujaoude, E., Large, M. D., \&Serpe, R. T. (2006). Estimated prevalence of compulsive buying behavior in the United States. American Journal of Psychiatry, 163(10), 1806-1812.

Lejoyeux, M., Tassain, V., Solomon, J., \&Adès, J., (1997). Study of compulsive buying in depressed patients. Journal of Clinical Psychiatry, 58(4), 169-173.

Lovibond, P. F., \&Lovibond, S. H. (1995). The structure of negative emotional states: Comparison of the Depression Anxiety Stress Scales (DASS) with the Beck Depression and Anxiety Inventories. Behaviour Research and Therapy, 33, 335- 343.

McElroy, S. L., Keck, P. E., Pope, H. G., Smith, J. M. R., Strakowski, S. M. (1994). Compulsive buying: a report of 20 cases. Journal of Clinical Psychiatry, 55, 242-8.

Mick, D. G. (1996). Are Studies of Dark Side Variables Confounded by Socially Desirable Responding? The Case of Materialism. Journal of Consumer Research, 23, 106-19.

Miltenberger, R., Redlin, J., Crosby, R., Stickney, M., Mitchell, J., Wonderlich, S., Faber, R., \& Smyth, J. (2003). Direct and retrospective assessment of factors contributing to compulsive buying. Journal of BehaviorTherapy and Experimental Psychiatry, 34(1), 19.

Mowen, J. C. \& Spears, N. (1999). Understanding compulsive buying among college students: A hierarchical approach, Journal of Consumer Psychology, 8, 407-430.

Mueller, A., Mitchell, J. E., Black, D. W., Crosby, R. D., Berg, K., deZwaan, M., (2010). Latent profile analysis and comorbidity in a sample of individuals with compulsive buying disorder. Psychiatry Research, 178(2), 348-353.

Mueller, A., Mitchell, J. E., Peterson, L. A., Faber, R. J., Steffen, K. J., \& Crosby, R. D. (2011). Depression, materialism, and excessive internet use in relation to compulsive buying. Comprehensive Psychiatry, 52, 420-424. 
Neuner, M., Raab, G., \&Reisch, L. (2005). Compulsive buying in maturing consumer societies: An empirical re-inquiry. Journal of Economic Psychology, 26, 509-522.

O’Guinn, T. \& Faber, R. (1989). Compulsive buying: a phenomenological exploration. Journal of Consumer Research, 16(2), 147-157.

Richins, M. L. \& Dawson, S. (1992). A consumer values orientation for materialism and its measurement: Scale development and validation. Journal of Consumer Research, 19, 305-316.

Ridgway, N. M., Kinney, M. \& Monroe, K. B. (2008). An expanded conceptualization and a new measure of compulsive buying. Journal of Consumer Research, 35(4), 622-39.

Roberts, J. A. (1998). Compulsive buying among college students: An investigation of its antecedents, consequences, and implications for public policy. Journal of ConsumerResearch, 12, 315-321.

Rose, P. (2007). Mediators of the association between narcissism and compulsive buying: the roles of materialism and impulse control. Psychology of Addictive Behaviors, 21(4), 576581.

Scherhorn, G., Reisch, L. A., Raab, G. (1990). Addictive buying in West Germany: an empirical study. Journal of Consumer Policy, 13, 355-87.

Schlosser, S., Black, D. W., Repertinger, S., \&Freet, D. (1994). Compulsive buying: Demography, phenomenology, and comorbidity in 46 subjects. General Hospital Psychiatry, 16, 205-212.

Valence, G., D'Astous, A., \& Fortier, L. (1988). Compulsive buying: Concept and measurement. Journal of Consumer Policy, 11(4), 419-433.

Williams, D. A. (2012). Evaluation of the mood repair hypothesis of compulsive buying. Open Journal of Psychiatry, 2, 83-90. doi:10.4236/ojpsych.2012.22012

Yurchisin, J. \& Johnson, K. K. (2004). Compulsive buying behaviour and its relationship to perceived social status associated with buying, materialism, self-esteem, and apparelproduct involvement. Family and Consumer Sciences Research Journal, 32, 291-314, doi: 10.1177/1077727X03261178. 